\title{
The Clinical and Radiological Effectiveness of Autologous Bone Marrow Derived Osteoblasts in the Management of Avascular Necrosis of Femoral Head in Sickle Cell Disease.
}

\section{Mir Sadat-Ali ( $\nabla$ drsadat@hotmail.com )}

College of Medicine, Imam AbdulRahman Bin Faisal University, Dammam https://orcid.org/0000-00018590-0830

\section{Abdallah S Al-Omran}

Imam Abdulrahman Bin Faisal University King Fahd Hospital of the University

\section{Sadananda Acharya}

Imam Abdulrahman Bin Faisal University

\section{Tarek M Hijazi}

Imam Abdulrahman Bin Faisal University King Fahd Hospital of the University

\section{Abid $\mathrm{H}$ Gullenpet}

Imam Abdulrahman Bin Faisal University King Fahd Hospital of the University

\section{Research}

Keywords: Stem cell, Osteoblasts, Avascular Necrosis of Femoral Head Osteonecrosis

Posted Date: February 11th, 2021

DOl: https://doi.org/10.21203/rs.3.rs-179614/v1

License: (c) (i) This work is licensed under a Creative Commons Attribution 4.0 International License.

Read Full License 


\section{Abstract}

Background and Objective: Avascular necrosis of femoral head is a common Issue faced by orthopaedic surgeons which ranges between $10-18 \%$ but in sickle cell Disease the incidence reaches $30 \%$. There is no definite treatment except joint arthroplasty. Regenerative medicine is an option to cure or delay joint arthroplasty. We report here our experience with injection of ABMDO to manage ANFH and report our long term results,progression of the ANFH if any and delay in THA (Total Hip Arthoplasty).

Patients and Methods: Sixty-Three (63) consecutive patients with SCD with ANFH were examined, thoroughly investigated and those who had ANFH < grade II were consented to receive ABMDO. Preoperatively patients were clinically assessed using Visual analogue scale (VAS), Modified Harris Hips Score (MHHS) and Azam-Sadat Score (ASS) for Quality of Life Score for Chronic Hip Disease. Ten milliliter of bone marrow was aspirated under local anesthesia and was placed in 20 CC culture media. Osteoblasts were cultured from the bone marrow aspirated. Under anesthesia using $3 \mathrm{~mm}$ cannulated drill, the osteonecrosed lesion was drilled and 5 million osteoblasts were injected at the lesion site. Patients were evaluated in out patient clinic after two weeks. At four months a repeat MRI was done and patients were followed up a minimum for 2 years.

Results: The average age was $25.93 \pm 5.48$ years. There were $41(65 \%)$ females and $22(35 \%)$ males. The mean hemoglobin $S$ was $83.2 \pm 5.1$ percent. The average follow up was $49.05 \pm 12.9$ ( range 24-60) months. VAS significantly improved from $7.79 \pm 1.06$ at 2 weeks $4.07 \pm 1.08 p<0.0001$ continued to improve for the next 24 months $2.38 \pm 0.55$ ( $P<0.0001)$. MHHS improved from $41.77 \pm 5.37$ to $73.19 \pm 6.48$ at 4 months $(P<0.001)$ and at 24 months it was $88.93 \pm 3.6(p<0.001)$. The ASS also significantly improved from $2.76 \pm 0.49$ preoperatively to $7.92 \pm 0.09(p<0.0001)$ at 24 months. A comparison of the MRI's of before and after osteoblast implantation revealed new bone formation and amelioration of the avascular lesions. Three patients were unhappy with the outcome and one patients repeated attacks of the vasoocclusive crisis within six months of the osteoblasts injection.

Conclusions: The results give credence to our earlier short follow up results that osteoblasts transplantation has a great potential in healing of avascular lesions. Our study fits the criteria of Phase II clinical trial and We believe a larger study equivalent to Phase III numbers and include patients not only with sickle cell disease but also steroid induced and idiopathic avascular necrosis.

\section{Introduction}

Avascular of the femoral head (ANFH) as the name suggest is the insult to the head of femur which results in the interruption of the blood supply leading to necrosis. Many diseases and drugs like steroids have been blamed. In general the true incidence of ANFH is not know but in US it is reported that up to 600,000 people are affected and every year another 20,000 new cases are diagnosed..$^{1-3}$ The figures coming out from China are startling of 8.12 million cases of non traumatic ANFH annually. ${ }^{4}$ In the Middle east and in particular majority ANFH occur in patients with hemoglobinopathies like SCD. The reported 
incidence of ANFH in SCD patients in Saudi Arabia is in the range of 25-30\% and many of the patients are affected are in the late teens. ${ }^{5}$

Many treatments have been tried in the past decades to relieve symptoms of pain and mobility, like core decompression, ${ }^{6-9}$ core decompression and bone graft ${ }^{10}$, vascularized bone graft ${ }^{11}$, extracorporeal shock therapy ${ }^{12}$, bisphosphonate therapy to delay the collapse of the head of femur. ${ }^{13}$ Since many of the procedures lived up to the expectations, clinicians were on the lookout for alternative methods. Bone marrow derived stem cells appeared a good option for regenerate the avascular head. The Meta analysis of Li et al (2014) ${ }^{14}$ showed that such a treatment was feasible and effective. An earlier study published from our institution with a short-term follow up showed similar results. ${ }^{15}$

The aim of this work is to report the long-term results of the clinical treatment of ANFH using autologous bone marrow derived osteoblasts.

\section{Patients And Methods}

The Institutional Review Board (IRB) of Imam AbdulRahman Bin Faisal University, Dammam, and Saudi Arabia gave the approval of the present study. Sixty-Three (63) consecutive patients with SCD with osteonecrosis of the head of femur were examined, thoroughly investigated and those who had ANFH < grade II were consented to receive ABMDO. Pre-operatively patients were clinically assessed using MHHS and ASS. Ten CC of bone marrow aspiration was performed under local anesthesia and was placed in 20 $\mathrm{CC}$ culture media. Osteoblasts were cultured from the bone marrow aspirated. When the ABMDO were ready of injection patients were re admitted to the hospital. Patients had exchange transfusion to bring the Hemoglobin S fewer than $50 \%$ before injection of osteoblasts. The procedure for the culture of the osteoblasts is described elsewhere. ${ }^{1}$ Surgical Procedure: Under anesthesia, patients were placed in the lateral position with the affected hip up. Two guide wires were passed the area of maximum avascular area. The acceptable wire was over drilled with $3 \mathrm{~mm}$ cannulated drill, the guide wire was removed and the cannulated drill was withdrawn till beginning of the neck. The drilled portion was washed with normal saline using a long catheter. The drilled was sucked out of any remaining saline. Using a long catheter 5 million osteoblasts were transplanted slowly. The cannulated drill was further withdrawn and $0.5 \mathrm{ml}$ saline was further pushed through the drill. After 4-5 minutes the cannulated drill was removed. The drill site at the skin was closed using $3 / 0$ nylon. Patients were discharged the same evening. Patients were evaluated in out patient clinic after two weeks. At four months patients were examined in the out patients clinics for Azam-Sadat score (ASS) ${ }^{16}$ for Quality of Life Score for Chronic Hip Disease was MHHS A Magnetic Resonance Imaging (MRI) was done for both hips. Patients were regularly followed in the out patient clinics. Two musculoskeletal radiologists reviewed the MRI independently and reported the films.

Statistical Analysis: The data was entered in the database and analyzed using the Statistical Package for Social Sciences software, version 23.0 (SPSS Inc, Chicago, IL, USA). Data was presented as a mean \pm standard deviation (SD). The mean values with $95 \%$ confidence intervals $(\mathrm{Cl})$ for each assay results were calculated, and a $p$-value of $<0.05$ was considered as significant. 
The Data is available at the dsr@iau.edu.sa.

The data of the study can be assessed at the Deanship of Scientific Research (dsr@iau.edu.sa) of Imam AbdulRahman Bin Faisal University, Dammam.

\section{Results}

The average age was $25.93 \pm 5.48$ years. There were $41(65 \%)$ females and $22(35 \%)$ males. The mean hemoglobin $S$ was $83.2 \pm 5.1$ percent. Table I gives the demographic data of 63 patients. The average follow up was 40.05 \pm 8.9 ( range 24-48) months. VAS significantly improved from $7.79 \pm 1.06$ at 2 weeks $4.07 \pm 1.08 p<0.0001$ continued to improve for the next 24 months $2.38 \pm 0.55(P<0.0001)$. MHHS improved from $41.77 \pm 5.37$ to $73.19 \pm 6.48$ at 4 months $(P<0.001)$ and at 24 months it was $88.93 \pm 3.6(p<0.001)$. The ASS also significantly improved from $2.76 \pm 0.49$ preoperatively to $7.92 \pm 0.09(p<0.0001)$ at 24 months. Table II shows the three parameters assessed preoperatively and at 2 weeks, 4 months and 24 months.

Overall 59 (93.6\%) were satisfied with improved quality of life and 4 (6.4\%) were unsatisfied as their disease progressed and had to have total hip replacement (Table III). The failure of the four patients could be due to the re-insult to the head of femur due to vaso-occlusive crisis. A comparison of the MRI's of before and after osteoblast implantation revealed new bone formation and amelioration of the avascular lesions. (Figures I-III)

\section{Discussion}

Our long-term results indicate that osteoblasts have the potential to reverse the avascular lesions in the head of femur in patients with sickle cell disease. Secondly majority of the patients were satisfied and in $4(6.4 \%)$ of the patients underwent THA due to progression of the disease process. The failure could be due to the progression of the disease due to the re-insult on the head of femur due to vaso-occlusive crisis. The remaining patients at the last visit were not progressing.

Hernigou and Beaujean ${ }^{17}$ used bone marrow concentrate injections, which contains mesenchymal stromal cells with standard core decompression and reported that those 60 months only in $6.2 \%$ (9 of 145 hips) the disease progressed and had required joint replacement. We believe that patients with SCD who get repeated vaso-occlusive crisis may end up in failure and may need repeat injections. A 2018 study of Kang and his colleagues ${ }^{18}$ of comparative study between core decompression versus bone marrow mesenchymal stem cell (BMMSC) implantation and found that 20\% progressed to clinical failure stem cell group, while $50 \%$ of the hips with only core decompression progressed to clinical failure. These reports indicate the bone marrow derived osteoblasts/Mesenchymal Stem Cells (MSC) can reverse the avascular lesions improved MHHS, VAS and quality of life in majority of patients and secondly it delays the THA. 
There is universal concern about the safety of stem cell therapies and its side effects. Most of the concerns come from the allogenic stem cells, which can cause

tumors and heterotopic ossification. ${ }^{19-21}$ However autologous stem cell therapy is safer than allogeneic stem cell transplants, as autologous cells are safer and reduce the probability of side effects. This has been proved in long-term results. ${ }^{22}$

This study has limitations. Firstly there was no comparison between the conventional core decompression and ABMDO patients and secondly we did not reach the minimum of Phase II of the United State Food and Drug Authority (USFDA) requirement. But the strength of our study being a prospective nature and a longer follow. Lastly in this study we had subjective and objective assessments, which indicated that immensely, improved results. Even though we were apprehensible of our results because of the SCD, which can have, re-insults of the hip due to VOC. In these series our 4 patients who failed is probably due to the re-insults on the head of femur as a sequeale of VOC. In conclusion, the use of ABMDO resulted in the improvement of VAS, MHHP, ASS and desirable changes in the head of affected femur as seen in the MRI.

\section{Conclusion}

In conclusions, the results of this study give credence to our earlier short follow up results that osteoblasts transplantation has a great potential in healing of avascular lesions. Our study fits the criteria of Phase II clinical trial and we believe a larger study equivalent to Phase III numbers should be undertaken and also include patients not only with sickle cell disease but also steroid induced and idiopathic avascular necrosis.

\section{Abbreviations}

Autologous Bone Marrow Derived Osteoblasts (ABMDO)

Avascular Necrosis of Femoral Head (ANFH)

Total Hip Arthoplasty (THA)

Visual Analogue Scale (VAS)

Modified Harris Hips Score (MHHS)

Azam-Sadat Score (ASS)

IRB= Institutional Review Board (IRB)

Magnetic Resonance Imaging (MRI)

Statistical Package for Social Sciences software (SPSS) 
Confidence intervals $(\mathrm{Cl})$

Bone Marrow Mesenchymal Stem Cell (BMMSC)

Mesenchymal Stem Cell (MSC)

United State Food and Drug Authority (USFDA)

\section{Declarations}

Ethical approval was given by the Institutional Review Board of Imam AbdulRahman Bin Faisal University, Dammam and informed written consent was obtained from all the patients for publication and usage of data and MRI and filed in the patients medical records. (This will be produced if needed)

Availability of data and material: is available at dsr@iau.edu.sa.

Funding: There was no funding obtained for this study.

\section{Authors' contributions}

The Two authors MSA and ASO are orthopaedic surgeons who aspirated bone marrow and injected the osteoblasts. The concept and writing up was done MSA.

SA. Stem cell consultant cultured the osteoblasts from the bone marrow aspirate.

TMH and AHG: The musculoskeletal radiologist who reviewed the MRI's blinded and reported.

Participated in the literature review and final manuscript.

\section{Competing Interests}

The authors declare that they have no competing interests.

\section{References}

1. Moya-Angeler J, Gianakos AL, Villa JC, Ni A, Lane JM. Current concepts on osteonecrosis of the femoral head. World J Orthop. 2015;6(8):590-601 Epub 2015/09/24. 区

2. Shah KN, Racine J, Jones LC, Aaron RK. Pathophysiology and risk factors for osteonecrosis. Curr Rev Musculoskelet Med. 2015;8(3):201-9 Epub 2015/07/06. 《

3. Mankin HJ. Nontraumatic necrosis of bone (osteonecrosis). N Engl J Med. 1992;326(22):1473-9.】

4. Zhao DW, Yu M, Hu K, Wang W, Yang L, Wang BJ, et al. Prevalence of Nontraumatic Osteonecrosis of the Femoral Head and its Associated Risk Factors in the Chinese Population: Results from a Nationally Representative Survey. Chin Med J. 2015;128(21):2843-50 Epub 2015/11/03. 『 
5. Sadat-Ali M. Avascular necrosis of the femoral head in sickle cell disease. An integrated classification.Clin Orthop Relat Res. 1993;(290):200-5

6. Iorio R, Healy WL, Abramowitz AJ, Pfeifer BA. Clinical outcome and survivorship analysis of core decompression for early osteonecrosis of the femoral head.J Arthroplasty.1998;13(1):34-41

7. Mazieres B, Marin F, Chiron P, Moulinier L, Amigues JM, Laroche M, et al. Influence of the volume of osteonecrosis on the outcome of core decompression of the femoral head.Ann Rheum Dis. 1997;56(12):747-50.

8. Mont MA, Jones LC, Pacheco I, Hungerford DS. Radiographic predictors of outcome of core decompression for hips with osteonecrosis stage III. Clin Orthop Relat Res. 1998;(354):159-68

9. Pierce TP, Jauregui JJ, Elmallah RK, Lavernia CJ, Michael A, Mont MA, et al. A current review of core decompression in the treatment of osteonecrosis of the femoral head. Curr Rev Musculoskelet Med. 2015 Sep; 8(3): 228-232.

10. Wei BF, GeXH. Treatment of osteonecrosis of the femoral head with core decompression and bone grafting.Hip Int. 2011 21(2):206-10.

11. Cao L, Guo C, Chen J, Chen Z, Yan Z. Free Vascularized Fibular Grafting Improves Vascularity Compared With Core Decompression in Femoral Head Osteonecrosis: A Randomized Clinical Trial. Clin Orthop Relat Res 2017 ;475(9):2230-40.

12. Sanjay Agarwala S, Shah SB. Ten-year follow-up of avascular necrosis of femoral head treated with alendronate for 3 years. J Arthroplasty 2011;26(7):1128-34.

13. Wang CJ, Huang CC, Wang JW, Wong T, Yang YJ. Long-term results of extracorporeal shockwave therapy and core decompression in osteonecrosis of the femoral head with eight- to nine-year followup. Biomed J. 2012; 35(6):481-5.

14. Li X, Xu X, Wu W. Comparison of bone marrow mesenchymal stem cells and core decompression in treatment of osteonecrosis of the femoral head: a meta-analysis. Int J Clin Exp Pathol. 2014;7(8):5024-30

15. Sadat-Ali M, Azam MQ, Elshabouri EM, Tantawy AM, Acharya S. Stem Cell Therapy for AvascularNecrosisof Femoral Head in Sickle Cell Disease: Report of 11 Cases and Review of Literature. Int J Stem Cells. 2017 Nov 30;10(2):179-83.

16. Azam MQ, Sadat-Ali M. Quality of Life in Sickle Cell Patients After Cementless Total Hip Arthroplasty. The Journal of Arthroplasty 2016; 31: 2536-541.

17. Hernigou P, Beaujean F. Treatment of osteonecrosis with autologous bone marrow grafting. Clin Orthop Relat Res 2002;(405):14-23

18. Kang JS, Suh YJ, Moon KH, Park JS, Roh TH, Park MH et al. Clinical efficiency of bone marrow mesenchymal stem cell implantation for osteonecrosis of the femoral head: a matched pair control study with simple core decompression. Stem Cell Res Ther 2018 Oct 25;9(1):274.doi: $10.1186 /$ s13287-018-1030-y 
19. Yin Zi, Hu J-J, Yang L, Zheng Z-F, An C-R, Wu B-B et al. Single-cell analysis reveals a nestin+tendon stem/progenitor cell population with strong tenogenic potentiality. Sci Adv $2016 \mathrm{Nov}$ 18;2(11):e1600874.doi: 10.1126/sciadv.1600874

20. Shimono K, Tung WE, Macolino C, Chi AH-T, Didizian JH, Mundy C et al. Potent inhibiion of heterotopic ossification by nuclear retinoic acid recep- tor-y agonists. Nat Med 2011;17(4): 454-60.『

21. Berkowitz AL, Miller MB, Mir SA, Cagney D, Chavakula V, Guleria I, et al. Glioproliferative lesion of the spinal cord as a complication of "stem-cell tourism. N Engl J Med 2016;375:196-8.

22. WakitaniS, Okabe T, Horibe S, Mitsuoka T, Saito M, Koyama T et al. Safety of autologous bone marrow-derived mesenchymal stem cell transplantation for cartilage repair in 41 patients with 45 joints followed for up to 11 years and 5 months. J Tissue Eng Regen Med 2011 Feb;5(2):146-50.

23. Wong RSY. Mesenchymal stem cells: angels or demons? J Biomed Biotechnol 2011 doi:10.1155/2011/459510

\section{Tables}

Table I: Demographic data of all patients.

\begin{tabular}{|ll|}
\hline Age (Years): & $25.93 \pm 5.48$ \\
\hline Females: & 41 \\
\hline Males: & 22 \\
\hline Ficat I: & 5 \\
\hline Ficat II: & 47 \\
\hline Ficat III: & 11 \\
\hline Follow Up (Months): & $40.05 \pm 8.9$ (range 24-48) \\
\hline
\end{tabular}

Table Il: Assessment of Pre and Post ABMDO Transplantation

\begin{tabular}{|lllll|}
\hline Parameter & $\begin{array}{l}\text { Pre } \\
\text { Operative }\end{array}$ & 16 & Post Operative (Weeks) \\
104 & 2 \\
\hline VAS & $7.79 \pm 1.06$ & $4.07 \pm 1.08$ & $3.38 \pm 0.72$ & $2.38 \pm 0.55$ \\
\hline MHHS & $41.77 \pm 5.37$ & $49.9 \pm 4.92$ & $73.19 \pm 6.48$ & $84.8 \pm 5.22$ \\
\hline ASS & $2.76 \pm 0.49$ & $4.85 \pm 0.87$ & $6.2 \pm 0.59$ & $7.92 \pm 0.90$ \\
\hline
\end{tabular}

VAS=Visual Analogue Scale, MHHS= Modified Harris Hip Score, ASS=Azam-Sadat Score

Table 3: Overall Satisfaction of All Patients 


\begin{tabular}{|ll|}
\hline Level of satisfaction & No.(\%) \\
\hline Extremely Satisfied & $42(66.6)$ \\
\hline Very Satisfied & $11(17.5)$ \\
\hline Satisfied & $6(9.5)$ \\
\hline Not Satisfied & $4(6.4 \%)$ \\
\hline
\end{tabular}

\section{Figures}

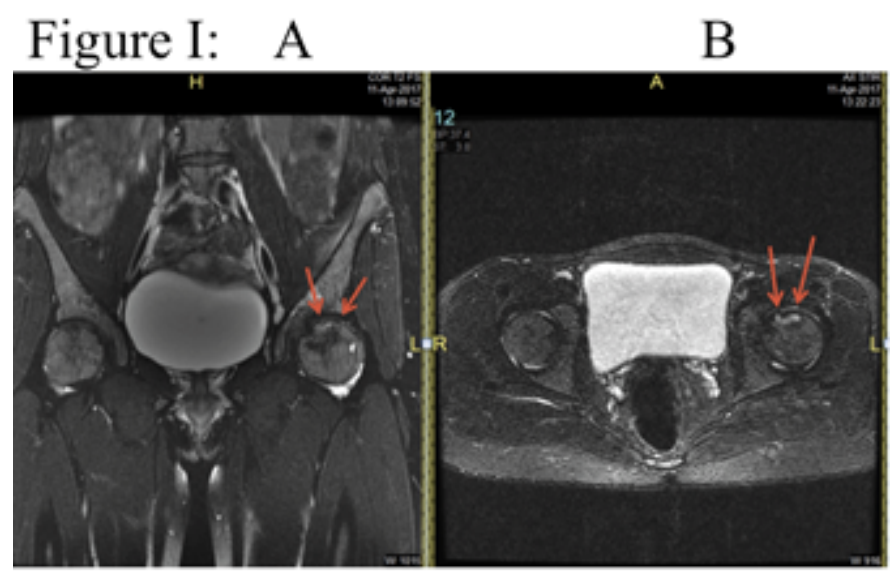

\section{Figure 1}

IA Coronal Short-TI Inversion Recovery image and IB) Axial T2 weighted fat suppressed image of the left hip demonstrates a geographic subchondral area of ANFH in the anterior-superior aspect of the left femoral head. There is no significant subchondral collapse of the femoral head articular surface. IC and D: (C) Coronal Short-TI Inversion Recovery image and (D) Axial T2 weighted fat suppressed image of the left hip performed 2 years after demonstrates near complete resolution of the femoral head AVN. IIA and B: A Coronal T1 weighted image of the pelvis demonstrates a large geographic area of ANFH in the anterior-superior aspect of the left femoral head. There is no significant subchondral collapse. (B) Coronal T1 weighted image perfomed 4 months after demonstrates interval improvement of femoral head ANFH. IC: MRI done after 30 months. Coronal Short-TI Inversion Recovery image demonstrates near complete resolution of the femoral head ANFH. 
Figure III D

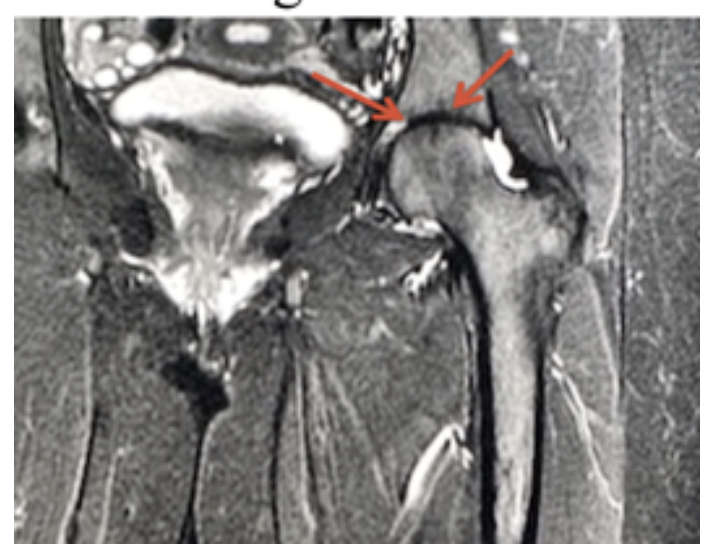

\section{Figure 2}

IIIA: (A) Coronal T1 fat suppressed image of the pelvis demonstrates a geographic area of abnormal signal intensity in the left femoral head (red arrows) compatible with ANFH IIIB: Coronal T1 weighted image performed 4 Months after demonstrates interval improvement of ANFH as well ghost tracts from prior drilling through which osteoblasts were transplanted (red arrows). IIIC: Coronal Short-TI Inversion Recovery weighted image performed 18 Months after demonstrates further interval improvement in surface area involvement of the left femoral head involvement by ANFH (red arrows). IIID: Coronal ShortTI Inversion Recovery weighted image performed 36 Months after demonstrates complete resolution of the femoral head ANFH (red arrows). 